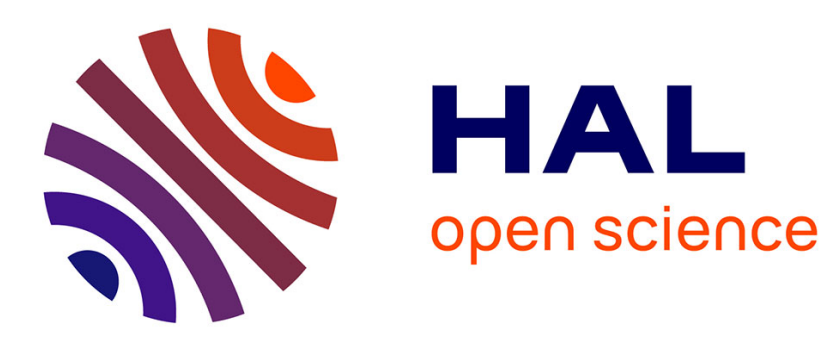

\title{
Thermal Behavior of High Power GaAs-Based Laser Diodes in Vacuum Environment
}

\author{
J Michaud, L Béchou, D Veyrié, F Laruelle, S Dilhaire, S Grauby
}

\section{To cite this version:}

J Michaud, L Béchou, D Veyrié, F Laruelle, S Dilhaire, et al.. Thermal Behavior of High Power GaAs-Based Laser Diodes in Vacuum Environment. IEEE Photonics Technology Letters, 2016, 28 (6), pp.665-668. 10.1109/LPT.2015.2504394 . hal-01343339

\section{HAL Id: hal-01343339 \\ https://hal.science/hal-01343339}

Submitted on 8 Jul 2016

HAL is a multi-disciplinary open access archive for the deposit and dissemination of scientific research documents, whether they are published or not. The documents may come from teaching and research institutions in France or abroad, or from public or private research centers.
L'archive ouverte pluridisciplinaire HAL, est destinée au dépôt et à la diffusion de documents scientifiques de niveau recherche, publiés ou non, émanant des établissements d'enseignement et de recherche français ou étrangers, des laboratoires publics ou privés.

\section{다(1)(2)}

Distributed under a Creative Commons Attribution - ShareAlikel 4.0 International 


\title{
Thermal Behavior of High Power GaAs-Based Laser Diodes in Vacuum Environment
}

\author{
J. Michaud, L. Béchou, D. Veyrié, F. Laruelle, S. Dilhaire, and S. Grauby
}

\begin{abstract}
Since 980-nm GaAs-based laser diodes are now implemented in space missions, there is a huge need to study their thermal behavior under vacuum in order to evaluate their reliability. Then spatially resolved temperature variations have been evaluated by thermoreflectance on the front facet under atmospheric and vacuum conditions, and for two different unpumped windows lengths. We show that, in all cases, vacuum induces a front facet temperature variation increase of the laser diodes, making them more sensitive to a catastrophic optical damage.
\end{abstract}

Index Terms-Vacuum environment, facet temperature variation, laser diode, unpumped window.

\section{Context And Motivation}

$\mathbf{H}$ IGH power density GaAs-based pump laser diodes emitting at $980 \mathrm{~nm}$ are currently used in distribution network transmission systems in Erbium-Doped Fiber Amplifiers [1] for long distance and large capacity optical telecommunication systems but also in space missions for Fiber Optic Gyroscopes, intra-satellite communication links,... [2]. There is hence a need to study how vacuum environment can affect their reliability.

Qualification testing of high power 808nm pump laser diode arrays in vacuum environment was reported, revealing no catastrophic failures [3], [4]. The authors concluded that these laser diodes are robust enough to survive in the harsh space environment. More recently [5], reliability tests were performed on $980 \mathrm{~nm}$ laser diodes with a specific focus on long-term $\mathrm{CW}$ aging under vacuum. The chip was a spatially single mode $980 \mathrm{~nm}$ laser diode housed in a hermetically sealed butterfly package with dual-lens coupling optics. Because the chip was embedded into a sealed package, it was not directly exposed to vacuum environment but depending on the package leak rate, the internal pressure could vary from its initial value

J. Michaud, S. Dilhaire, and S. Grauby are with the Laboratoire Ondes et Matière d'Aquitaine, University of Bordeaux, Talence 33405, France (e-mail: jmichaud25@gmail.com; stefan.dilhaire@u-bordeaux.fr; stephane.grauby@u-bordeaux.fr).

L. Béchou is with the Laboratoire de l'Intégration du Matériau au Système, University of Bordeaux, Talence 33405, France (e-mail: laurent.bechou@ims-bordeaux.fr).

D. Veyrié is with the Centre National d'Etudes Spatiales, Toulouse 31041, France (e-mail: david.veyrie@cnes.fr).

F. Laruelle is with 3S Photonics, Nozay 91625, France (e-mail: flaruelle@ 3spgroup.com).

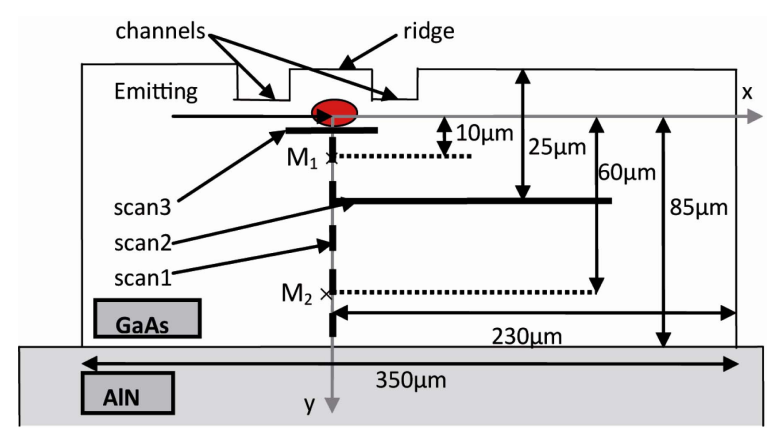

Fig. 1. Generic facet view of the laser diode.

to the external pressure one. Eight packaged diodes were studied and among them, four were specifically punctured before the aging test to accelerate the out-diffusion of gaseous contents and to simulate the behavior of the laser diode after a long high vacuum exposition at $10^{-7}$ mbar. After the test, the non-punctured components were fully operational whereas, among the modules of the punctured group, three out of four had suddenly failed. The main mechanisms originating from the failure were investigated, leading to the conclusion that a front facet temperature increase due to the lack of convection effect under vacuum was the probable root cause of degradation, leading to a Catastrophic Optical Damage (COD). In a previous paper [6], we showed that the unpumped window (UPW) length had an influence in the front facet temperature distribution and that a longer UPW could make the laser diode less sensitive to COD.

In this letter, we hence particularly investigate the thermal behavior of these devices in air and under vacuum. Temperature variations of unpackaged $980 \mathrm{~nm}$ laser diodes are estimated on different positions of the front facet using a spatially resolved thermoreflectance (TR) technique, for two kinds of laser diodes with different UPW lengths, under atmospheric conditions, and for the first time, under vacuum.

\section{Experimental Set Up and Devices Under Test}

The devices under test (fig.1) are single $\mathrm{AlGaAs} / \mathrm{InGaAs}$ quantum well laser diodes emitting at $980 \mathrm{~nm}$ [7]. The $3.9 \mathrm{~mm}$ long ridge structure, covered by a gold layer, allows to confine the current and the light emission in the quantum well of the active region at the $\mathrm{p}-\mathrm{n}$ junction, thus reducing the threshold current. The front facet reflectivity is typically $1 \%$, which is a classical value for high power laser diodes. We studied two kinds of devices, differing by their UPW length, either 


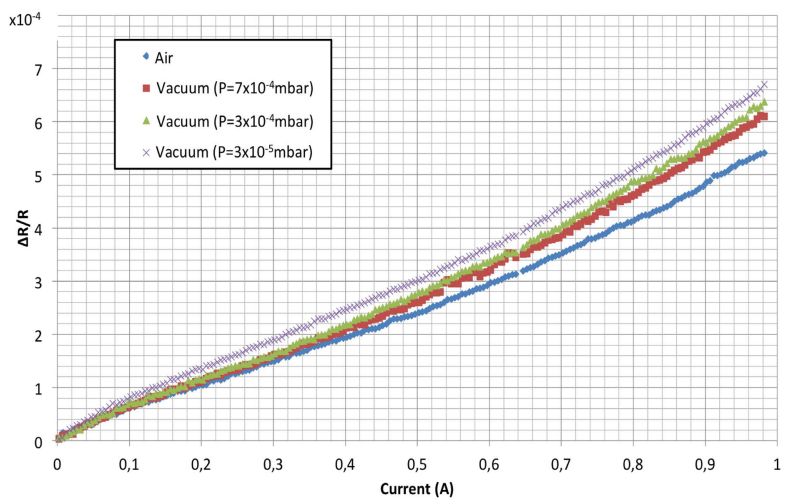

Fig. 2. TR signal versus bias current $I_{\max }$ for different vacuum levels.

short (noted S-UPW) or long (noted L-UPW). S-UPW diodes are identical to the ones studied in [5]. The S-UPW is much smaller than the $30 \mu \mathrm{m}$ long UPW studied in [8] whereas the L-UPW has been lengthened with a diode power reduction limited to $1 \%$ at maximum.

The diodes are biased by a driving current which is a $50 \%$ duty cycle square current $(\mathrm{f}=442 \mathrm{~Hz})$ varying from $0.1 \mathrm{~mA}$ to $\mathrm{I}_{\max } ; \mathrm{I}_{\max }$ can be adjusted from $6 \mathrm{~mA}$ to $1 \mathrm{~A}$. Then, the electrical power is mainly dissipated at frequency $f$, which induces a temperature variation at the same frequency $\Delta \mathrm{T}_{\mathrm{f}}$, and consequently a reflectivity variation $\Delta R_{f}$ [9], [10]. The relative reflectivity variation is related to $\Delta \mathrm{T}_{\mathrm{f}}$ according to:

$$
\frac{\Delta R_{f}}{R}=\frac{1}{R} \frac{\partial R}{\partial T} \Delta T_{f}=\kappa \times \Delta T_{f}
$$

where $\mathrm{R}$ is the sample mean reflectivity and $\kappa$ is the thermoreflectance coefficient mainly depending on the nature of the material and on the probe light wavelength. Subsequently, $\Delta \mathrm{R}_{\mathrm{f}} / \mathrm{R}$ and $\Delta \mathrm{T}_{\mathrm{f}}$ are simply noted $\Delta \mathrm{R} / \mathrm{R}$ and $\Delta \mathrm{T}$ respectively and $\Delta R / R$ is evaluated through the relative intensity variations of a probe beam reflected at the diode under test surface. We measured the thermoreflectance signal for increasing frequencies; we noted a low-pass filter thermal behavior and the frequency $\mathrm{f}=442 \mathrm{~Hz}$ lies inside the bandwidth. This frequency, as well as the duty cycle, were chosen to reach the steady state regime. To operate under vacuum, we added to the detailed thermoreflectance set-up described in [6] a vacuum chamber where the laser diode under test is positioned. This chamber can work down to $10^{-6} \mathrm{mbar}$. When the device is positioned in the chamber, its pressure is stabilized around $3 \times 10^{-5}$ mbar. The lab-made vacuum chamber is equipped with an input quartz window and an inside micrometric translation stage to displace the laser diode under test. We use a $632 \mathrm{~nm}$ (wavelength for which $\kappa$ is maximum) $\mathrm{He}-\mathrm{Ne}$ laser as a probe and a $\times 20$ magnitude microscope objective for which the spot diameter was evaluated to $3 \mu \mathrm{m}$ approximately. The quartz window imposes a relatively high working distance (several $\mathrm{mm}$ ) which prevents from using a high magnification objective. The $\Delta \mathrm{R} / \mathrm{R}$ set-up sensitivity was measured to be as low as $2 \times 10^{-6}$.

First, the TR signal is measured as a function of the bias current, $I_{\max }$ varying from $6 \mathrm{~mA}$ to $1 \mathrm{~A}$ with a $3 \mathrm{~mA}$ step when the probe beam is focused at around $\mathrm{y}=15 \mu \mathrm{m}$ on

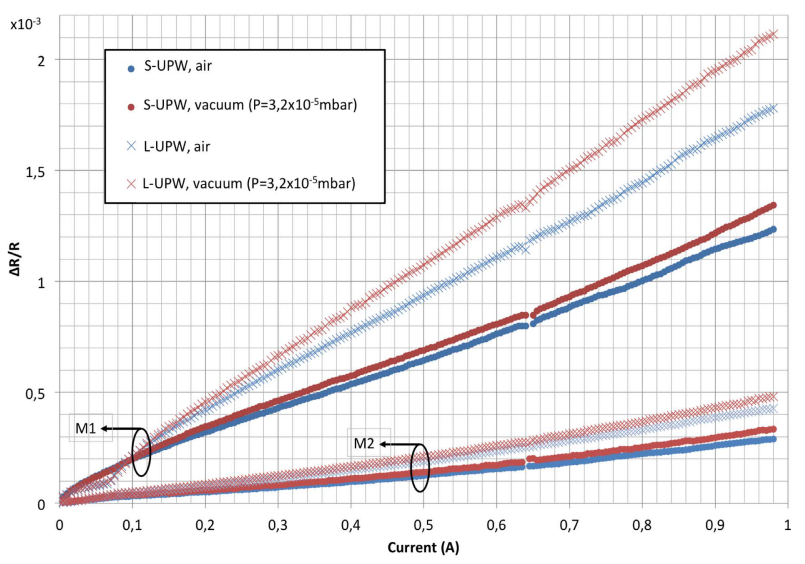

Fig. 3. TR signal versus bias current $I_{\max }$ in air and vacuum for the S-UPW and L-UPW diodes and for two different locations in the front facet.

the $y$ axis. This measurement is done for 4 different pressure levels on a S-UPW diode: atmospheric pressure, $7 \times 10^{-4} \mathrm{mbar}$, $3 \times 10^{-4} \mathrm{mbar}$ and $3 \times 10^{-5} \mathrm{mbar}$ (fig.2). When the pressure level decreases, we clearly note an increase of the TR signal, thus of the temperature variation $\Delta \mathrm{T}$, up to $24 \%$. A pressure influence is then obvious. Subsequently, all the "vacuum" measurements are done under a $3.2 \times 10^{-5}$ mbar pressure.

\section{VACUum Impact on LASER Diode Temperature VARIATION MEASUREMENTS}

All the measurements presented below were done on 3 laser diodes of each type and repeated three times. The curves correspond to the calculated mean values. Whatever the pressure conditions (air or vacuum), the measurements are done with the laser diode inside the vacuum chamber under the same optical conditions. Let us underline that the experimental conditions of the measurements under atmospheric conditions are different from the measurements in [6] since they are done inside the vacuum chamber and with a $\times 20$ magnitude microscope objective.

\section{A. Influence of the Bias Current on the TR Signal}

Since the thermal behavior is expected to be different far from the emitting zone and close to it [11], we first focused on two particular positions: one close $(10 \mu \mathrm{m})$ to the emitting source $\left(\mathrm{M}_{1}\right)$ and one $60 \mu \mathrm{m}$ far from it $\left(\mathrm{M}_{2}\right)$ as indicated in fig.1. For each position, we measured the TR signal magnitude as a function of the maximum current, $\mathrm{I}_{\max }$ varying from $6 \mathrm{~mA}$ to $1 \mathrm{~A}$ with a $3 \mathrm{~mA}$ step (fig.3). Let us recall that 3 parts can be distinguished in these curves [12]: a first linear part under the threshold current $\left(\mathrm{I}_{\text {th }}=67 \mathrm{~mA}\right)$ with slope $\alpha_{1}$, then a second linear part with slope $\alpha_{2}$ and finally a non-linear part. The transition current for which the curve goes from the second linear behavior to the non-linear behavior is noted $\mathrm{I}_{\mathrm{t}}$. Above $\mathrm{I}_{\mathrm{th}}$, the front facet temperature variations are due to two heat sources: the ridge linear source and the emitting zone surface source which can be at the origin of a COD.

The $\alpha_{2} / \alpha_{1}$ ratio is an indicator of this last heat source: the higher $\alpha_{2} / \alpha_{1}$, the greatest the emitting zone heat source. 
TABLE I

Thermoreflectance Measurements in Air and Under VacuUm

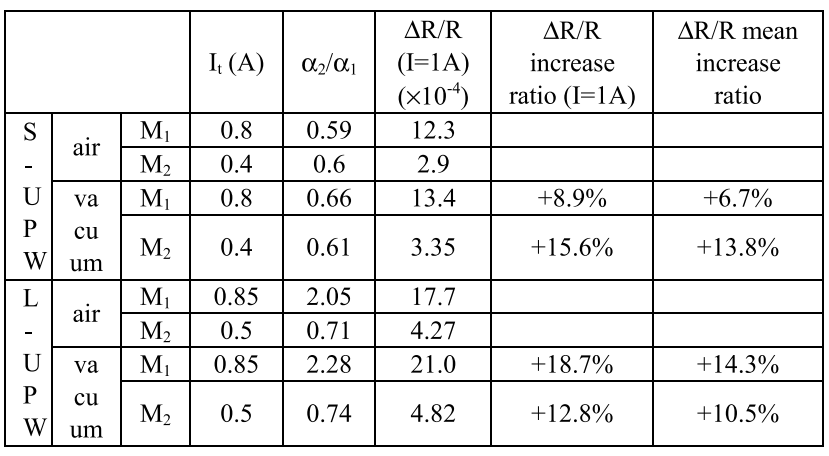

We note that whatever the position and the UPW length, the $\mathrm{TR}$ signal, hence $\Delta \mathrm{T}$, is higher under vacuum than under air environment. Table 1 summarizes the main results obtained both under atmospheric conditions and under vacuum: $\mathrm{I}_{\mathrm{t}}$ value, $\alpha_{2} / \alpha_{1}$ ratio, TR signal at maximum current $\left(I_{\max }=1 \mathrm{~A}\right)$, TR signal increase ratio at $\mathrm{I}_{\max }=1 \mathrm{~A}$ between air and vacuum conditions, and mean TR signal increase ratio between $\mathrm{I}_{\text {th }}$ and $1 \mathrm{~A}$.

For S-UPW diodes, the TR signal increases from $6.7 \%$ to $15.6 \%$. This rate is higher at position $\mathrm{M}_{2}$ but it is less critical than for position $\mathrm{M}_{1}$, for which the absolute TR signal, therefore the absolute $\Delta \mathrm{T}$, is higher. Concerning the L-UPW diodes, the TR signal increase reaches $18.7 \%$ at position $\mathrm{M}_{1}$, from $(17.7 \pm 0.02) \times 10^{-4}$ in air to $(21.0 \pm 0.02) \times 10^{-4}$ under vacuum, which is even more critical than for the S-UPW diode. The transition current $\mathrm{I}_{\mathrm{t}}$, indicating the onset of the non-linear behavior leading to thermal runaway, is slightly dependent on the UPW length but is not affected by the pressure level. In contrast, the $\alpha_{2} / \alpha_{1}$ ratio increases under vacuum by a small amount at position $\mathrm{M}_{2}$ but by more than $10 \%$ for position $\mathrm{M}_{1}$ whatever the UPW length. Then, for both probed positions, vacuum conditions induce a $\alpha_{2} / \alpha_{1}$ ratio increase but also a TR signal increase, hence a $\Delta \mathrm{T}$ increase from $6.7 \%$ to almost $20 \%$, leading to an expected higher sensitivity to COD under vacuum.

\section{B. Front Facet Temperature Variation Distribution}

In [6], it was demonstrated that the $\Delta \mathrm{T}$ distribution is different when S-UPW and L-UPW diodes are compared: for the S-UPW diodes, the heat is more concentrated very close to the emitting zone, which would make it more sensitive to COD. We propose now to evaluate how this temperature variation distribution is affected by the vacuum environment for both kinds of UPW. We first measured (fig.4) the TR signal along the $\mathrm{y}$ axis when $\mathrm{I}_{\max }=800 \mathrm{~mA}(\operatorname{scan} 1)$. The first point ( $y=2 \mu \mathrm{m})$ corresponds to the bottom of the emitting source towards the AlN heat sink. The displacement step is $3 \mu \mathrm{m}$ for the first step and then $5 \mu \mathrm{m}$ between $\mathrm{y}=5 \mu \mathrm{m}$ and $80 \mu \mathrm{m}$.

We clearly see that the TR signal, hence $\Delta \mathrm{T}$, is higher under vacuum than in air for both UPW lengths. For the S-UPW diode, the mean increase along the whole vertical scan is almost $10 \%$ but the increase near the emitting zone

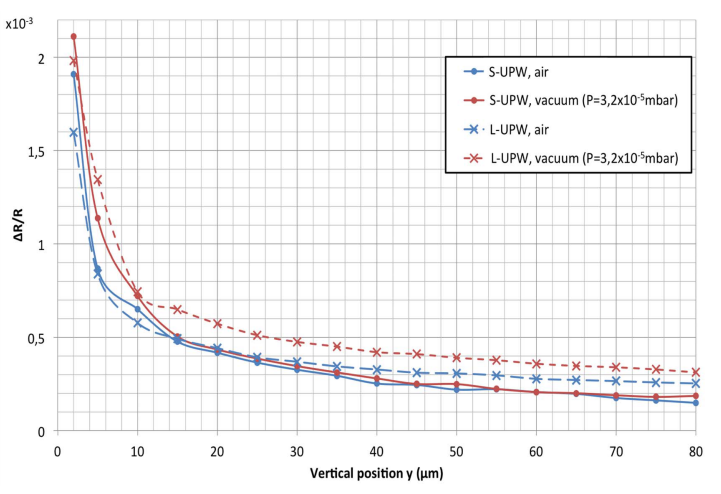

Fig. 4. TR signal along the $y$ axis $\left(I_{\max }=800 \mathrm{~mA}\right)$ under air and vacuum for S-UPW and L-UPW diodes.

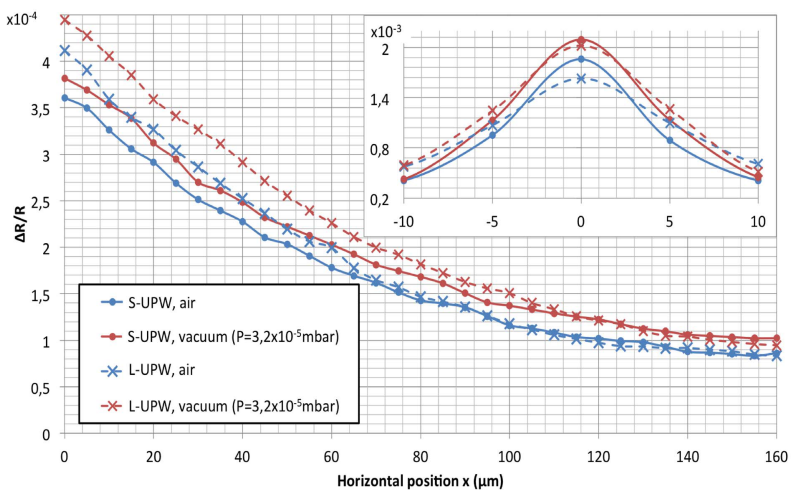

Fig. 5. TR signal $(\mathrm{y}=25 \mu \mathrm{m}, 0<\mathrm{x}<160 \mu \mathrm{m})$ at $\mathrm{I}_{\max }=800 \mathrm{~mA}$ under air and vacuum for S-UPW and L-UPW diodes. Inset: TR signal $(\mathrm{y}=2 \mu \mathrm{m}$, $-10 \mu \mathrm{m}<x<10 \mu \mathrm{m})$.

$(2 \mu \mathrm{m}<y<10 \mu \mathrm{m})$ reaches $31.0 \%$. As for the L-UPW diode, the increase near the emitting zone $(2 \mu \mathrm{m}<\mathrm{y}<10 \mu \mathrm{m})$ also reaches $32.0 \%$ but the mean increase is as high as $30.3 \%$. As previously noticed [6], we can see that, under atmospheric conditions, very close to the emitting zone, the S-UPW diode heats more than the L-UPW diode. This is also the case under vacuum even if the difference between S-UPW and L-UPW is not so marked.

We also measured the TR signal on an horizontal scan (scan2), along the black horizontal full line (fig.1), for $\mathrm{y}=25 \mu \mathrm{m}$ and between $\mathrm{x}=0 \mu \mathrm{m}$ and $\mathrm{x}=160 \mu \mathrm{m}$ with a $5 \mu \mathrm{m}$ step. Here again, the TR signal increases for both UPW lengths when measuring under vacuum. For the S-UPW and L-UPW diodes respectively the mean increase along the scan is $14.2 \%$ and $17.4 \%$ but it reaches a maximum value around $22.7 \%$ and $28.1 \%$. The TR signal is lower than in the previous scan because even the first point is relatively far from the emitting zone.

Then, to analyze the thermal behavior very close to the emitting zone, we measured (inset in fig.5) the TR signal on another horizontal scan for $\mathrm{y}=2 \mu \mathrm{m}$ and $-10 \mu \mathrm{m}<$ $x<10 \mu \mathrm{m}$ with a $5 \mu \mathrm{m}$ step (scan3). Once again, near the emitting zone, the S-UPW diode heats more than the L-UPW diode, both under atmospheric conditions and under vacuum. Moreover, for a same UPW length, we can note once 
TABLE II

TR SCAN VALUes in Air AND Under VacuUm

\begin{tabular}{|c|c|c|c|c|c|}
\hline \multicolumn{2}{|c|}{} & $\begin{array}{c}\text { Maximum } \\
\Delta \mathrm{R} / \mathrm{R}-\text { air } \\
\left(\times 10^{-4}\right)\end{array}$ & $\begin{array}{c}\text { Maximum } \\
\Delta \mathrm{R} / \mathrm{R}- \\
\text { vacuum } \\
\left(\times 10^{-4}\right)\end{array}$ & $\begin{array}{c}\text { Maximum } \\
\Delta \mathrm{R} / \mathrm{R} \\
\text { increase } \\
\text { ratio }\end{array}$ & $\begin{array}{c}\text { Mean } \Delta \mathrm{R} / \mathrm{R} \\
\text { increase } \\
\text { ratio }\end{array}$ \\
\hline $\begin{array}{c}\text { S- } \\
\text { U }\end{array}$ & scan1 & 19.1 & 21.1 & $+31.0 \%$ & $+9.1 \%$ \\
\cline { 2 - 6 } P & scan2 & 3.61 & 3.82 & $+22.7 \%$ & $+14.2 \%$ \\
\cline { 2 - 6 } W & scan3 & 18.6 & 21.0 & $+27.5 \%$ & $+14.5 \%$ \\
\hline L- & scan1 & 16.0 & 19.8 & $+32.0 \%$ & $+30.3 \%$ \\
\cline { 2 - 6 } U & scan2 & 4.1 & 4.4 & $+28.1 \%$ & $+17.4 \%$ \\
\cline { 2 - 6 } & scan3 & 16.3 & 20.2 & $+24.1 \%$ & $+14.3 \%$ \\
\hline
\end{tabular}

again a large TR signal increase under vacuum. This increase is about the same for both kinds of diode: almost $15 \%$ for the mean increase and around $25 \%$ for the maximum increase under vacuum close to the emitting zone.

Table II summarizes the results of the three scans. First, under vacuum, as well as under atmospheric conditions, the heat seems differently distributed between the S-UPW and the L-UPW diode: the S-UPW diode would heat more near the emitting zone whereas the heat would be more homogeneously distributed on the whole facet for the L-UPW, in accordance with results presented in [6].

In addition, all the measurements lead to the conclusion that the laser diodes heat more under vacuum than under atmospheric conditions whatever the position on the front facet and whatever the UPW. The mean $\Delta \mathrm{T}$ increase is higher for the L-UPW diode. Nevertheless, near the emitting zone, the maximum increase is about the same for both kinds of diodes, up to $32 \%$, and the absolute maximum TR signal is always higher for S-UPW diodes, making them more vulnerable to COD than L-UPW diodes.

In conclusion, under vacuum, all the laser diodes are submitted to higher temperature variations on their facet considering the same operating conditions than for air conditions, which could make them more sensitive to COD and constitute one of the possible causes for the failure of the punctured devices observed in [5]. Further investigations are in progress to carefully analyze the physical mechanism of such failure which is completely different from well-known random failure modes commonly accepted for GaAs based laser diodes.

\section{ACKNOWLEDGMENT}

The authors would like to warmly thank Dr. J. L. Gauffier and S. Reyjal from the Department of Physics Engineering at INSA-Toulouse, for the design of the dedicated vacuum chamber used in this study.

\section{REFERENCES}

[1] E. Desurvire, J. R. Simpson, and P. C. Becker, "High-gain erbium-doped traveling-wave fiber amplifier," Opt. Lett., vol. 12, no. 11, pp. 888-890, Nov. 1987.

[2] S. Rougelot, S. Mariojouls, T. Buret, D. Ramecourt, and X. Calmet, "Procurement and qualification of optical components for space fibre optic gyroscope application," in Proc. 1st Int. Symp. Rel. Optoelectron. Space, Cagliary, Italy, 2009, pp. 231-236.

[3] E. Troupaki, A. Vasilyev, N. B. Kashem, G. R. Allan, and M. A. Stephen, "Space qualification and environmental testing of quasicontinuous wave laser diode arrays," J. Appl. Phys., vol. 100, no. 6, pp. 063109-1-063109-5, 2006.

[4] Y. Durand, A. Culoma, R. Meynart, J.-L. Pinsard, and G. Volluet, "Performance of high-power laser diode arrays for spaceborne lasers," Appl. Opt., vol. 45, no. 22, pp. 5752-5757, 2006.

[5] G. Pedroza et al., "Long term in-vacuum reliability testing of $980 \mathrm{~nm}$ laser diode pump modules for space applications," presented at the 35th IEEE Aerosp. Conf., Big Sky, MT, USA, Mar. 2014, pp. 1-14.

[6] J. Michaud et al., "Precise facet temperature distribution of high-power laser diodes: Unpumped window effect," IEEE Photon. Technol. Lett., vol. 27, no. 9, pp. 1002-1005, May 1, 2015.

[7] M. A. Bettiati, "High optical strength GaAs-based laser structures," Microelectron. Rel., vol. 53, nos. 9-11, pp. 1496-1500, 2013.

[8] F. Rinner et al., "Facet temperature reduction by a current blocking layer at the front facets of high-power InGaAs/AlGaAs lasers," J. Appl. Phys., vol. 93, no. 3, pp. 1848-1850, 2003.

[9] S. Dilhaire, S. Grauby, and W. Claeys, "Thermoreflectance calibration procedure on a laser diode: Application to catastrophic optical facet damage analysis," IEEE Electron Device Lett., vol. 26, no. 7, pp. 461-463, Jul. 2005.

[10] P. W. Epperlein, "Mapping of local temperatures on mirrors of GaAs/AlGaAs laser diodes," Inst. Phys. Conf. Ser., vol. 112, no. 8, pp. 633-638, 1990.

[11] S. Dilhaire, S. Grauby, S. Jorez, L.-D. P. Lopez, E. Schaub, and W. Claeys, "Laser diode COFD analysis by thermoreflectance microscopy," Microelectron. Rel., vol. 41, nos. 9-10, pp. 1597-1601, Oct. 2001

[12] S. Dilhaire, S. Grauby, and W. Claeys, "Thermoreflectance calibration procedure on a laser diode: Application to catastrophic optical facet damage analysis," IEEE. Electron Device Lett., vol. 26, no. 7, pp. 461-463, Jul. 2005. 